\title{
0 alongamento do tempo de prisão e a violação de direitos na custódia de presos no Brasil
}

\author{
The Extension of Prison Time and the Uiolation of Rights in Custody \\ of Prisoners in Brazil \\ El alargamiento del tiempo de prisión y la violación de derechos \\ en la custodia de presos en Brasil
}

\author{
Flavio Medeiros Rangel, Pedro Paulo Gastalho Bicalho* \\ Universidade Federal do Rio de Janeiro
}

Doi: http://dx.doi.org/10.12804/revistas.urosario.edu.co/apl/a.4304

\section{Resumo}

O presente artigo teve por objetivo analisar alguns aspectos da racionalidade política que rege o sistema prisional brasileiro na atualidade. Para isso, tomaram-se como objeto de pesquisa, os relatórios de inspeções realizadas em estabelecimentos penais brasileiros pelo Conselho Nacional de Política Criminal e Penitenciária entre 2011 e 2012. A análise do alongamento do tempo de prisão possibilitou inferir a lógica, não somente limitada às prisões, mas expandida por todo o corpo social, direcionada, principalmente, àqueles à margem da produção e do consumo. Por isso, a prisão, tal como se observou, funciona como efeito que conserva a função de reprodução desta racionalidade.

Palavras-chave: crime, prisão, políticas públicas, problemas sociais. fbstract

The presented article aims to analyze some perspectives of the political rationality that governs the Brazilian prison system in the actuality. To this end, reports of inspections in Brazilian penal establishments made between 2011 and 2012 by the National Council for Criminal and Penitentiary Policy were taken as the research object. The analysis of the extension of prison time made it possible to infer that the logic is not limited to prisons, but exists within the society instead, particularly directed at those at the margin of production and consumption. Therefore the prison as observed is the effect and it retains its function of reinforcing this rationality.

Keywords: Crime, prison, public policies, social issues.

* Correspondência. Correio eletrônico: ppbicalho@gmail.com

Cómo citar este artículo: Rangel, F. M., \& Bicalho, P. P. G. (2017). O alongamento do tempo de prisão e a violação de direitos na custódia de presos no Brasil. Avances en Psicología Latinoamericana, 35(3), 473-483. doi: http://dx.doi.org/10.12804/ revistas.urosario.edu.co/apl/a.4304 


\section{Resumen}

El presente artículo tuvo como objetivo analizar algunos aspectos de la racionalidad política que rige el sistema penitenciario brasileño en la actualidad. Para esto, se tomaron como objeto de investigación los relatos de inspecciones realizadas en establecimientos penales brasileños por el Consejo Nacional de Política Criminal y Penitenciaria entre 2011 y 2012. El análisis del alargamiento del tiempo de prisión posibilitó inferir la lógica no solamente limitada a las prisiones, sino expandida por todo el cuerpo social, direccionada, principalmente, a aquellos al margen de la producción y del consumo y, por eso, tal como se observó, actúa como efecto que conserva la función de reproducción de esta racionalidad.

Palabras clave: crimen, prisión, políticas públicas, problemas sociales.

\section{Introdução}

No Brasil, no início do ano de 2015, contabilizavam-se 622 mil pessoas encarceradas, sendo a quarta maior população prisional do mundo, atrás apenas dos Estados Unidos (2,2 milhões), da China (1,6 milhão) e da Rússia (740 mil). Entre janeiro de 1992 e junho de 2013, enquanto a população cresceu $36 \%$, o número de pessoas presas aumentou 403,5\%. A imensa maioria de presos que compõem a massa carcerária são de homens, jovens, pobres, negros/pardos, de baixa escolaridade e moradores de periferias de grandes cidades (Reishoffer \& Bicalho, 2015). Para complementar, constata-se que ainda restam 325207 mandados de prisão a serem cumpridos.

Tais números não são ao acaso, visto que estão em acordo com a lógica da penalidade neoliberal, dentro do sistema capitalista atual. Analisando a sociedade norte-americana, Wacquant (2011) constatou o recrudescimento de estratégias de segregação punitiva em face ao retrocesso de políticas sociais, o que levou a população carcerária americana a triplicar em quinze anos, chegando a índices de encarceramento de 650 detentos por 100000 habitantes em 1997. Esta nova programática penal, que potencializou a hipertrofia do encarceramento, possui motivações e corre em paralelo com a redução drástica do Estado social, a partir da metade da década de 1970, período em que tem início a implementação do modelo socioeconômico neoliberal.

O neoliberalismo adotou como diretriz a plena liberdade aos mercados, viabilizados pela globalização das instituições bancárias e financeiras, pelo emprego de novas tecnologias para intensificar as operações globais e pela utilização de tecnologias avançadas de comunicação, que têm a potencialidade de duplicar o capital produtivo (Arguello, 2007). O modelo capitalista neoliberal passa a impor novas relações de consumo e produção, impõe programas de aumento da produtividade, que flexibilizam e precarizam as relações de trabalho, produzindo uma debilitação dos direitos econômicos, sociais e culturais, com elevação do desemprego e do emprego informal. Assim, constata-se que uma conjuntura estruturada sob a égide da liberdade de mercado, em conjunto com a flexibilização de direitos individuais e sociais, produz como efeito colateral a descartabilidade do valor "pessoa humana" e o retorno a um estado pré-civilizatório, no qual impera a lei do mais forte (Carvalho, 2008), neste caso, aquele com maiores poderes para produzir e consumir.

A redução da rede de segurança social nos países centrais, como também os sucessivos cortes orçamentários na assistência social, na saúde pública, na educação e na moradia, trouxe como efeito direto o incremento das funções penais e policiais do Estado sobre aquelas populações antes assistidas. Tal efeito com forte deslocamento de recursos públicos de áreas sociais para a área de segurança pública, visou manter políticas basicamente repressivas e punitivas, que envolveram e fortaleceram tanto o setor penitenciário, como o judiciário e o policial (Kilduff, 2010). Ou seja, as 
questões econômicas e sociais perdem a intervenção estatal, saem dos programas de manutenção da ordem pública, instaurando uma insegurança social coletiva em grandes parcelas da população. Aqueles que já dispunham precariamente das mínimas garantias de sobrevivência, agora irão compor a imensa lista de desempregados ou subempregados, sendo assim denominados "excluídos". Entretanto, Forrester (1997), contrariamente, afirmará que, em vez de excluídos, os miseráveis estão totalmente incluídos nas lógicas neoliberais:

E como alguns os querem ainda mais apagados, riscados, escamoteados dessa sociedade, eles são chamados de excluídos. Mas, ao contrário, eles estão lá, apertados, encarcerados, incluídos até a medula! Eles são absorvidos, devorados, relegados para sempre, deportados, repudiados, banidos, submissos e decaídos, mas tão incômodos: uns chatos! Jamais completamente, não, jamais suficientemente expulsos! Incluídos, e em descrédito (p. 15).

Com o enfraquecimento das proteções sociais e aumento do desemprego e do mercado informal, o Estado redefinirá seu papel, adotando políticas que fortalecem e hipertrofiam o chamado "Estado Penal". Wacquant (2011) caracteriza cinco condições de possibilidade para a "hipertrofia" do Estado Penal americano, a saber: (i) a expansão vertical do sistema, revelada pelo crescimento de pessoas privadas de liberdade, com cumprimento de pena no interior das prisões; (ii) a expansão horizontal da rede penal, observada pelo aumento das medidas de penalização extramuros através das "liberdades" condicional e vigiada; (iii) o crescimento do setor penitenciário no seio das administrações públicas, revelando a política de "ação afirmativa carcerária"; (iv) o rigor aumentado em relação aos crimes vinculados à drogas e à população negra, e; (v) a privatização carcerária, propiciando um mercado emergente para toda uma rede de serviços de vigilância, alimentos, seguro, serviços, administração, manutenção, arquitetura, financiamento, construção, transporte.
Visando potencializar as análises de Wacquant (2011), o presente estudo analisa, a partir de dados referentes ao encarceramento no Brasil, o que seria a sexta condição de possibilidade de hipertrofia do Estado Penal: o alongamento do tempo de prisão. Pretende-se, com este artigo, acrescentar mais um item à lista de Wacquant e, assim, cumprir o objetivo de lançar luz sobre a racionalidade política - a razão produtora das práticas políticas observadas em determinado contexto (Foucault, 2008) - que tem hegemonicamente regido o sistema prisional brasileiro.

\section{Descrição de práticas como caminho de pesquisa}

Procurou-se compreender, com a presente pesquisa, as práticas promovidas aos homens e mulheres em cumprimento de pena ou medida privativa de liberdade no Brasil, pois o fato de se encontrarem em tal condição os torna alvos de uma série de políticas, legislações, restrições e expectativas específicas, possibilitando circunscrever uma racionalidade política que recai, exclusivamente, sobre esta população. Dado que a passagem pelo sistema penal é produtora de forte estigma, estes sujeitos também sofrem importantes processos de criminalização ${ }^{1}$.

Foucault (2008), ao tratar do exercício da soberania política, mostra como a arte de governar sofreu mudanças importantes entre os séculos XVI e XVII e, como resultado, não mais se dá segundo leis divinas, e sim por um princípio de cálculo. Se antes a perspectiva presente era a do soberano, agora ela tem como base exclusiva o comportamento dos governados. Passam a determinar a prática

Dornelles (1992), em contraposição aos processos de incriminação, onde com base na lei ocorre a sanção penal de determinados comportamentos, apresenta a noção de processos de criminalização, em que leis não necessariamente jurídicas (e não necessariamente escritas em algum lugar), criam condutas desviantes e fazem operar punições cotidianas que não passam pelo aparato legal. 
governamental os efeitos esperados na população ao invés de categorias transcendentais. Deste modo, toda ação política tem por objetivo regular comportamentos, influenciando-os no sentido mais interessante economicamente. Daí a possibilidade de se falar em uma racionalidade política que rege a prática de governo, ou seja, um modo de governo não tolhido por tradições ou leis fundamentais, tendo por guia a razão.

Deste modo, o presente artigo tem como objetivo elucidar alguns aspectos da racionalidade política, que rege a população carcerária no Brasil. Para isto, os relatórios de inspeção referentes aos anos de 2011 e 2012, emitidos pelo Conselho Nacional de Política Criminal e Penitenciária (CNPCP) do Brasil $^{2}$, foram utilizados como dispositivo de acesso à realidade prisional brasileira, totalizando 18 relatórios que, juntos, abrangem 123 estabelecimentos penais em 18 unidades federativas, distribuídos como representados na figura 1. A população de detentos abrangida por estes relatórios foi de 68266 , os quais contemplam $8,32 \%$ do total de estabelecimentos penais no país e $12,46 \%$ do total de presos.

2 Por meio dos Conselhos, procura-se que propostas e temas de interesse da sociedade civil sejam incluídos na pauta do governo e, por fim, convertidos em políticas públicas. $\mathrm{O}$ CNPCP é composto por treze membros designados por meio de ato do Ministério da Justiça, dentre professores e profissionais da área do Direito Penal e ciências afins, bem como representantes da sociedade civil e ministérios do governo vinculados a causas sociais. Seus mandatos têm duração de dois anos. Atualmente, possui entre seus membros, integrantes dos Ministérios da Saúde, de Desenvolvimento Social e Combate à Fome, da Cultura e da Secretaria de Direitos Humanos da Presidência da República, além do próprio Ministério da Justiça. Ao longo dos dois anos de mandato, o membro do CNPCP realiza, dentre outras atividades, diversas inspeções em variados estabelecimentos penais. A cada visita, que costuma durar entre um e três dias, um único relatório é produzido, descrevendo a(s) inspeção(ões) realizada(s) naquela localidade. Os relatórios sempre contêm recomendações feitas pelos integrantes do CNPCP, visando sanar irregularidades encontradas ou mesmo a melhoria geral dos estabelecimentos visitados. Podem conter também a descrição de reuniões com autoridades locais, que porventura tenham ocorrido durante o período de estadia.

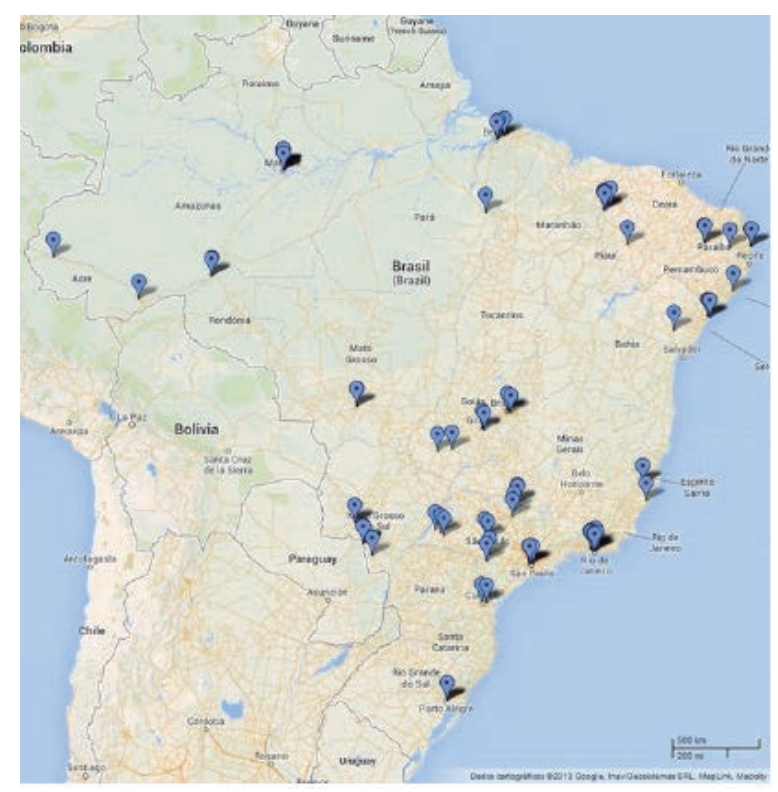

Figura 1. Estabelecimentos penais inspecionados pelo CNPCP contemplados na pesquisa

\section{Sistematização dos dados}

Tendo a pesquisa como objetivo traçar uma análise a nível nacional, cada relatório haveria de contribuir para visualização do cenário prisional no país. Desta forma, optou-se pela sistematização dos dados por meio de uma tabela, permitindo assim, a padronização das informações colhidas, rápido acesso a elas e manutenção das particularidades de cada estabelecimento penal inspecionado, porém ainda sob o risco de que estas particularidades fossem perdidas em meio à necessidade de enquadrar as informações. Procurando aproveitar esses dados não categorizados em cada unidade, foram criados campos na tabela para observações e comentários específicos.

As categorias foram construídas com base nos próprios relatórios e nas informações que se mostraram mais claras e frequentes em todos eles. Cabe aqui observar que, além das particularidades de cada estabelecimento penal, a falta de padronização dos relatórios do CNPCP apresentou-se como um desafio a ser superado no momento de estipular as 
informações que constariam na tabela. Isto porque, segundo observado, cada responsável pelo relatório pôde escrevê-lo à sua maneira, elencando diferentes dados para compor a descrição dos estabelecimentos ou focando em certos aspectos da inspeção, que por outros poderiam ser ignorados. Sendo assim, apesar de que teria sido enriquecedor para o trabalho informar, por exemplo, o tipo de regime a que se destina cada estabelecimento inspecionado (se fechado, aberto, semiaberto ou se abriga presos provisórios), ou se o estabelecimento é terceirizado, estas informações só foram incluídas quando claramente especificadas.

Ainda quanto à falta de padronização dos relatórios, verificou-se grande variabilidade na escolha das informações para compor a descrição dos estabelecimentos inspecionados, sendo alguns relatórios muito mais detalhados que outros nesse sentido. Dentre as informações não contempladas por todos os relatórios estão, por exemplo, o endereço dos estabelecimentos, formação profissional dos diretores das unidades, número de agentes penitenciários, quantidade de profissionais de saúde, frequência do banho de sol, periodicidade das visitas, e outras mais. Assim como se destinada ao sexo masculino ou feminino, a lotação e capacidade da unidade estão entre as informações mais presentes em todos os relatórios, mas nenhuma delas é contemplada pela totalidade destes.

O fato dos relatórios não apresentarem formatos únicos pode indicar que também as inspeções não seguem os mesmos padrões. Desta forma, é possível que certas questões não tenham sido verificadas em todas as visitas, como, por exemplo, a qualidade da alimentação, uma vez que alguns relatórios informam se boa ou ruim, enquanto outros não chegam a mencionar o assunto. Portanto, pode-se presumir que haja mais irregularidades nas unidades do que aquelas relatadas pelo CNPCP.

Outra importante observação a ser feita é quanto à indicação na tabela da presença ou não de irregularidades. Houve o cuidado de não inferir que determinadas situações consistiam problemas do ponto de vista do CNPCP, em especial quando não apontadas como tais pelas equipes de inspeção. Por exemplo, para o Centro de Detenção Provisório de Ribeirão Preto, estado de São Paulo, o relatório informa que há dois advogados para atendimento aos presos, porém não deixa claro se esta quantidade seria suficiente para atender adequadamente à demanda por assistência jurídica. Em caso semelhante, o relato de inspeção na Cadeia Pública Feminina de Franca, também em São Paulo, informa que 30 dentre as 216 presas ganham remição de pena pelo trabalho que fazem, mas não menciona se as oportunidades de trabalho oferecidas seriam adequadas à quantidade de detentas ou à demanda. Sendo assim, estas situações e outras similares não foram indicadas como irregularidades na tabela.

Definidas as categorias e contabilizadas suas ocorrências nos relatórios, assim ficaram distribuídas as frequências:

Ao longo da sistematização dos dados, situações analisadoras que fazem emergir a racionalidade política do sistema prisional brasileiro foram surgindo. Segundo Lourau (1993), analisadores são acontecimentos que "fazem aparecer, de um só golpe, a instituição "invisível” (p. 35). No caso deste artigo, trata-se da análise do alongamento do tempo de prisão, por ser este um elemento que transversaliza duas importantes formas de precariedade: a superlotação (presente em 67,5\% dos relatórios analisados) e presença deficitária do poder judiciário (em 17,1\% dos relatórios analisados), como demonstrados na tabela 1.

\section{Analisador alongamento do tempo na prisão}

"Cadeia vencida" é a expressão coloquial utilizada para fazer referência ao preso com sua situação jurídica em atraso. Isto é, seria possível ao preso com "cadeia vencida" progredir de regime (do fechado para o semiaberto ou deste para o aberto), ou mesmo ter direito à soltura quando já cumprido o tempo de reclusão. A Lei de Execução Penal 
Tabela 1

Frequências absolutas das ocorrências de irregularidades nos estabelecimentos penais inspecionados pelo CNPCP entre 2011 e 2012

\begin{tabular}{|c|c|c|c|c|c|c|c|c|c|c|c|c|c|c|c|}
\hline \multirow[b]{2}{*}{ 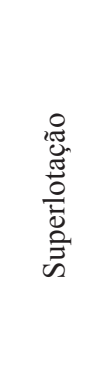 } & \multirow{2}{*}{ 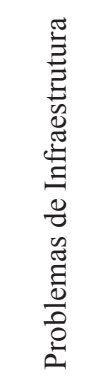 } & \multirow{2}{*}{ 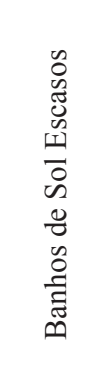 } & \multirow{2}{*}{ 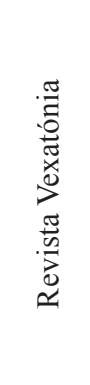 } & \multirow{2}{*}{ 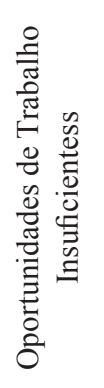 } & \multirow{2}{*}{ 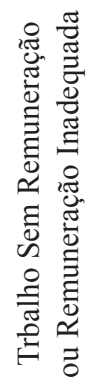 } & \multirow{2}{*}{ 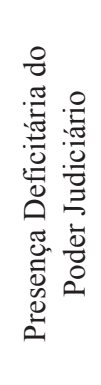 } & \multirow{2}{*}{ 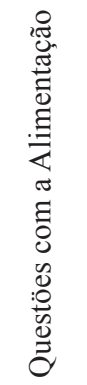 } & \multirow{2}{*}{ 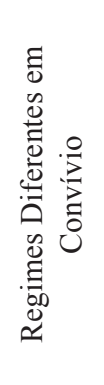 } & \multirow{2}{*}{ 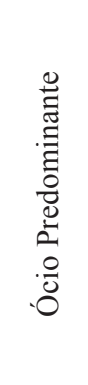 } & \multicolumn{6}{|c|}{ Precariedades da Assistência } \\
\hline & & & & & & & & & & 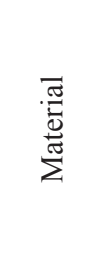 & 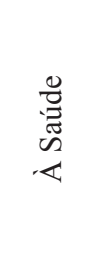 & 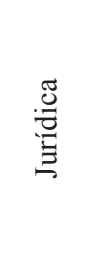 & 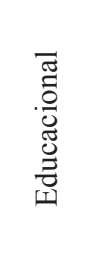 & $\begin{array}{l}\bar{\pi} \\
\frac{\pi}{0} \\
0 \\
\infty\end{array}$ & 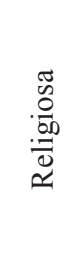 \\
\hline 83 & 65 & 17 & 17 & 19 & 9 & 21 & 23 & 17 & 19 & 59 & 49 & 42 & 36 & 39 & 1 \\
\hline $67,5 \%$ & $52,8 \%$ & $13,8 \%$ & $13,8 \%$ & $15,4 \%$ & $7,3 \%$ & $17,1 \%$ & $8,7 \%$ & $13,8 \%$ & $15,4^{c}$ & $48,0 \%$ & 39,8 & $34,1 \%$ & $29,3 \%$ & $31,7 \%$ & $0,8 \%$ \\
\hline
\end{tabular}

(LEP) (Brasil, 1984), afirma que a pena privativa de liberdade será executada em forma progressiva com a transferência para regime menos rigoroso, a ser determinada pelo juiz, quando o preso tiver cumprido ao menos um sexto da pena no regime anterior, e ostentar bom comportamento carcerário, comprovado pelo diretor do estabelecimento, respeitadas as normas que vedam a progressão.

No entanto, a progressão de regime nem sempre é observada pelas autoridades competentes, especialmente quando a capacidade do estabelecimento de acatar a demanda por assistência jurídica é maior que a própria demanda, situação comum segundo apontam os relatórios do CNPCP. Das unidades contempladas pela pesquisa, 42 apresentaram algum tipo de precariedade na capacidade de assistir juridicamente os presos (34,15\% do total). Paralelamente, observou-se que em 10 unidades a ocorrência de situações jurídicas em atraso foi claramente identificada no relatório $(8,13 \%)$, sendo que em seis dessas relatou-se também algum tipo de precariedade da assistência jurídica. Para as quatro demais, presume-se que o responsável pelo relatório não foi preciso em identificar a carência de assistência jurídica ou o atraso da situação jurídica dos presos se dê pela incapacidade do poder judiciário local de dar conta da demanda de processos, visto que a progressão de regime não depende unicamente do esforço feito no interior das prisões.

Embora a baixa ocorrência se comparados às demais irregularidades, os casos de "cadeia vencida" chamam atenção por grande parte deles ocorrer em estabelecimentos já superlotados ( 8 dos 10 observados). Ou seja, além do déficit de vagas e das condições ruins, há ainda presos permanecendo além do tempo devido, denotando grave violação de direitos e agravamento da conjuntura precária do sistema penitenciário brasileiro.

O relatório da inspeção do Centro de Inserção Social de Jataí, estado de Goiás, revela como nem sempre é a carência de recursos humanos a razão que mantém o condenado em privação de liberdade, mesmo quando poderia estar cumprindo a pena fora da prisão. No caso relatado, o juiz se recusa a substituir a pena privativa de liberdade por pena restritiva de direitos, devido ao fato de grande parte dos presos serem reincidentes no crime de tráfico de drogas, e Jataí ser região de rota do tráfico, embora a situação de superlotação da unidade tenha sido descrita como gritante: “ [...] lotação de 235 para uma capacidade de $66[\ldots]$ parte da superlotação decorre da peremptória negativa de substituição de penas, na 
tentativa de se fazer política criminal via judicial" (CNPCP, n. d.).

Para além das situações de perdura do condenado em determinado regime, ou mesmo preso quando poderia estar livre, há ainda a questão dos presos provisórios, que são aqueles que ainda aguardam término da instrução criminal e determinação da sentença (de apenamento ou absolvição). Em seu artigo 312, o Código de Processo Penal (Brasil, 1941) estabelece que a prisão preventiva pode ser decretada como garantia da ordem pública, da ordem econômica, por conveniência da instrução criminal, ou para assegurar a aplicação da lei penal, quando houver prova da existência do crime e indício suficiente de autoria ou ainda em caso de descumprimento de qualquer das obrigações impostas por força de outras medidas cautelares. No entanto, como destacam Pereira \& Mezzalira (2010), a lei é omissa em fixar o tempo de duração da prisão provisória e, como consequência, dá margem para dúvidas na interpretação do que seria um uso desproporcional desta medida. Argumentam ainda que, anteriormente à reforma do Código Processual Penal advinda em agosto de 2008, considerava-se 81 dias como prazo razoável para encerramento da instrução criminal. Entretanto, mesmo sendo o uso excessivo da prisão provisória uma questão importante no Brasil, haja vista a grande proporção de pessoas presas sob tal medida e sua duração pouco razoável, a reforma processual penal de 2008 permaneceu sem fixar limites para o tempo de prisão cautelar preventiva, alterando ainda os prazos dos procedimentos e impossibilitando a aplicação da doutrina dos 81 dias (Pereira \& Mezzalira, 2010).

Deste modo, para os presos provisórios, por ainda não terem sido julgados e, portanto, pela pena ainda não ter sido determinada, há certa dificuldade em apontar, durante inspeções, exatamente quando se trata de um caso de excesso de tempo de prisão ou não, diferentemente do que acontece com presos já julgados. Mesmo assim, foram constatadas inúmeras situações em que este prazo é alongado de maneira claramente desproporcional, como verificado, por exemplo, na Penitenciária Regional Padrão, do município de Campina Grande, no estado da Paraíba. Assim diz o relatório de inspeção:

Trata-se de penitenciária de regime fechado que abriga homens sem condenação, apenas provisórios, com capacidade para 150 apenados. No dia da inspeção do CNPCP havia 454 presos. Além da superlotação, outro grande problema nesta Unidade salta aos olhos: são presos provisórios, em média há mais de um ano sem audiência! Segundo a Direção e o Promotor que acompanhou as Conselheiras, o problema é da vara processante.

Situação semelhante foi encontrada nos presídios do estado do Mato Grosso inspecionados em 2012 (Centro de Ressocialização de Cuiabá, Presídio Central do Estado e Penitenciária Feminina Ana Maria do Couto May):

A falta de assistência jurídica foi alvo de muitos protestos por parte dos presos, sendo que constatamos que eles não possuem informações elementares acerca do andamento processual das ações penais em andamento, bem como das penas que eventualmente estejam cumprindo. Os relatórios encaminhados para a Ouvidoria do Sistema Penitenciário já demonstravam que esse é um grave problema no sistema prisional mato-grossense.

Durante as inspeções nas unidades visitadas, não houve nenhum lugar em que não constatamos a entrega pelos presos de pedaços de papel contendo seus nomes e reclamações acerca de benefícios não concedidos, excesso de prazo para a formação da culpa, dentre outros. Quando indagados se aguardavam há mais de seis meses para que fosse realizada a audiência de instrução e julgamento, vários detentos logo se identificavam. Noticiaram a extrema dificuldade em agendar atendimento com os Defensores Públicos designados para atuarem 
na execução penal, em face da superlotação carcerária, bem como em relatarem as mazelas do cárcere para o Juiz de Direito e para os Promotores de Justiça.

Mais casos de alongamento indefinido da prisão provisória foram verificados na Casa de Custódia Professor José Ribamar Leite, no município de Teresina, estado do Piauí, agravados pela superlotação da unidade:

Esse estado de coisas [superlotação e dificuldade de locomoção dos presos para suas Comarcas de origem] faz aumentar, por demais, o tempo de prisão provisória, gerando constantes reclamações dos presos. Muitos estão encarcerados há meses ou até anos, sem terem participado de uma única audiência sequer. Em rápido contato com os detentos, todos reclamaram do atraso de seu processo de conhecimento.

A lei prevê que, uma vez condenado, o tempo como preso provisório é subtraído da pena; entretanto, é possível que o preso seja inocentado ao final do processo. O período em que esteve recluso, porém, não terá sido simples acontecimento em sua existência. Como mostra Wacquant (2011) os danos causados pelo encarceramento não são poucos: há a estigmatização, vínculos são perdidos, estratégias escolares, matrimoniais e profissionais são interrompidas, famílias são desestabilizadas, além dos danos físicos e psicológicos, que muitas vezes deixam marcas profundas. Segundo dados do InfoPen ${ }^{3}$ de dezembro de 2012, o Brasil possui uma população de presos provisórios de 195 036, correspondendo a $35,59 \%$ da população carcerária

3 Infopen é um sistema de informações estatísticas do sistema penitenciário brasileiro, atualizado pelos gestores dos estabelecimentos desde 2004, que sintetiza informações sobre os estabelecimentos penais e a população prisional. Disponível em: http://dados.gov.br/dataset/infopen-levantamento-nacional-de-informacoes-penitenciarias/resource/ d2d3b792-49fe-4e30-84cd-38c81b000a2c total. Dado o grande número de processos, é de se esperar que nem todos resultem em condenações. $\mathrm{O}$ volume da massa encarcerada aguardando decisão judicial já se enunciaria como uma questão importante das políticas públicas, tendo a dimensão da questão relativa à sua situação maximizada pelas precárias condições existentes enquanto se espera pelas definições dos órgãos de justiça (Rossotti \& Bicalho, 2012).

As inspeções do CNPCP dificilmente seriam capazes de observar uma ocorrência de absolvição após período como preso provisório, pois seria necessário acompanhar o desdobramento dos processos penais até seus resultados finais. No entanto, se apresenta como um fato perfeitamente viável, uma vez que ainda não houve julgamento para estes presos. Um caso do tipo foi presenciado por Rossotti \& Bicalho (2012), em trabalho com presos provisórios da Carceragem de Nova Iguaçu:

E por mais um ano e sete meses esses acontecimentos se configuraram como as vivências diárias do preso em questão, até o dia marcado para receber sua sentença final, a qual seria: I-NOCEN-TE. Ele poderia finalmente considerar-se sem nenhum débito para com o sistema judicial e frente ao Estado. Porém, poderiam essas duas instituições tomar para si o mesmo veredicto? (p. 93).

Há ainda um terceiro fator observado nos relatórios de inspeção do CNPCP que contribui para o prolongamento do tempo de prisão: o fato de nem todos os presos terem acesso a trabalho e educação, duas atividades capazes de remir o tempo de pena. Segundo a LEP, o condenado que cumpre a pena em regime fechado ou semiaberto poderá remir, por trabalho ou por estudo, parte do tempo de execução da pena. A remição se dá por um dia de pena a cada três dias de trabalho e um dia de pena a cada 12 horas de frequência escolar, divididas, no mínimo, em três dias. 
Em seu artigo 41, que trata dos direitos do preso, a LEP estabelece como um dos direitos a atribuição de trabalho e sua remuneração. Já em seu artigo 83, determina que o estabelecimento penal, conforme a sua natureza, deverá contar em suas dependências com áreas e serviços destinados a dar assistência, educação, trabalho, recreação e prática esportiva. Dispõe ainda, como dever do Estado, prover assistência educacional, na forma de instrução escolar e formação profissional, e determina como obrigatório o ensino fundamental. A realidade, porém, se mostra bem diferente. Os dados de dezembro de 2012 do InfoPen mostram que apenas cerca de $20 \%$ da população carcerária total trabalha e menos de $10 \%$ está envolvida em alguma atividade educacional, sendo que cerca de $54 \%$ sequer possui o ensino fundamental completo.

Em 19, dos 123 estabelecimentos penais contemplados pela pesquisa, houve a clara constatação de que as oportunidades de trabalho na unidade eram insuficientes $(15,45 \%$ do total). Em três destas unidades o ócio é predominante entre os presos, isto é, grande parte deles não realiza qualquer atividade de trabalho, educacional ou lazer, muitos permanecendo na cela durante grande parte do tempo, inclusive sem banho de sol em muitos dos casos, como mostra o relato da inspeção na Penitenciária Doutor Romeu Gonçalves de Abrantes, em João Pessoa:

Não existem classes de estudo ou escola na Unidade. Disse a Direção que em 2012 alguns presos passarão a ter aulas, pois antes não tinham sala de aula nem biblioteca. Atualmente não há nenhum tipo de curso de educação para os internos, e são poucas as iniciativas da SEAP [Secretaria de Estado de Administração Penitenciária] neste sentido. [...]

Não existem oficinas de recreação, exercícios físicos, educação física, ou qualquer outra atividade neste sentido aos presos, sendo mesmo raro o seu banho de sol, conforme já se explicou acima. [...]
A ociosidade entre os detentos é muito grande nesta Unidade, sendo que em quase 600 presos apenas 18 trabalham, e só internamente, 11 na cozinha e 7 em serviços gerais.

Não existem oficinas de trabalho nesta Penitenciária, nada que possa oferecer aos presos a possibilidade de remição de pena através do trabalho. Em entrevistas, foi possível constatar o interesse da maioria dos internos em trabalhar, mas atualmente lhes é negada qualquer iniciativa concreta neste sentido por parte da SEAP.

Quanto à questão da remição de pena por estudo, 36 unidades $(29,27 \%)$ apresentaram algum tipo de precariedade na assistência educacional. Dos casos observados, há desde a completa ausência de ofertas de estudo até a limitação destas, em especial visando manter a segurança do estabelecimento, pois é comum que a superlotação seja posta como justificativa para limitar ou até mesmo coibir as atividades educacionais. Porém há situações em que, mesmo havendo o espaço para a atividade educacional, ela não acontece por falta de políticas de incentivo, como constatado nas inspeções feitas em unidades penais de Porto Alegre, estado do Rio Grande do Sul:

Outro ponto negativo durante a inspeção realizada nas unidades prisionais é a falta de assistência educacional, de atividades culturais e de lazer. Sem a oferta de educação e trabalho, os presos se submetem mais rapidamente aos efeitos da "prisionização", assim como perdem o direito à remição e, de consequência, a possibilidade de retorno mais célere para o convívio social, por meio de progressões de regime ou livramento condicional.

Não obstante a existência de professores interessados em educar os presos, não há uma política definida de incentivo à educação no interior dos presídios visitados. Diante disso, foram constatadas várias salas de aula vazias, sem qualquer atividade, 
ou pouco frequentadas. As entrevistas realizadas revelaram a persistência dos educadores, mas a fraca adesão por parte dos detentos. A título de exemplo, num universo de 4595 presos no PCPA [Presídio Central de Porto Alegre], apenas 172 presos frequentavam aulas de alfabetização, ensino fundamental ou médio; na PFMP [Penitenciária Feminina Madre Pelletier], das 280 presas somente 51 frequentavam essas aulas.

Das 36 unidades que apresentaram precariedades na assistência educacional, em 13 foi também constatada a ociosidade predominante entre os presos.

Wacquant (2011), citando investigação aprofundada sobre a trajetória carcerária feita em sete sítios penitenciários franceses, dá indícios de como a prisão produz miséria ao afrouxar vínculos, fragilizar relações e privar o detento de investimentos externos. Em geral, a entrada no cárcere é acompanhada da perda de trabalho e moradia, além da supressão parcial ou total de benefícios sociais, empobrecimento súbito, que necessariamente afetará de maneira negativa a família do detento. As transferências que se seguem no arquipélago penitenciário se traduzem em perdas ou confiscação de objetos pessoais e de dificuldade de acesso aos escassos recursos do estabelecimento. Por fim, a soltura marca novo empobrecimento, por seus custos inerentes e porque "revela brutalmente a miséria que o encarceramento havia temporariamente colocado entre parênteses" (Wacquant, 2011, p.152).

Deste modo, compreende-se a raridade do acesso a trabalho e educação nas prisões brasileiras, não apenas como privação do direito à remição de pena, mas principalmente como fragilização ainda mais incisiva dos laços externos já prejudicados pela situação, complementada pela predominância do ócio entre os presos, até o ponto máximo em que o único laço restante seja com o sistema penal, criando terreno fértil para a reincidência pós-soltura, contribuindo assim para o alongamento do tempo de prisão.

\section{Conclusões: inferências quanto à racionalidade política}

Vidas são desconsideradas - ou consideradas descartáveis - como aponta Alvarenga Filho (2013) pela condição de aprisionamento imposta pela execução penal. $\mathrm{O}$ alongamento do tempo de prisão revela racionalidade presente no sistema penal brasileiro, em que tais vidas constroem-se pela invisibilidade e, assim, perdem importância. Humanos, mas “não tão humanos assim". E é exatamente este o grande desafio da Psicologia (e das demais ciências humanas e sociais) frente ao tema dos direitos humanos: problematizar discursos e lógicas que valoram vidas por uma métrica em que umas parecem valer mais do que outras (Scisleski et al., 2012).

Segundo Baratta (2002), a finalidade da pena de prisão em promover a ressocialização do autor de um crime fracassou, por dois motivos principais: pelo fato de a prisão ter sido originariamente criada para promover a separação entre criminosos e sociedade (como se fosse uma oposição maniqueísta entre o Bem e o Mal), mas também pelos próprios clamores sociais, que provocam adoção de políticas contrárias a ideias de ressocialização e tratamento penal. $\mathrm{O}$ autor contesta, ainda, a ideia puramente individualista que aponta que a ressocialização envolveria, exclusivamente, a reforma do indivíduo para uma sociedade considerada sadia e naturalmente boa.

Não obstante, o paradoxo de retirarmos as pessoas do convívio social para "ensiná-las" a viver em sociedade, punimos os que não respeitaram a lei com um claro desrespeito ao que preconizam as leis penais do país. Racionalidades presentes no sistema penitenciário brasileiro, mas que não atingem somente as pessoas presas. Toda a sociedade é produzida a partir das lógicas que forjam 
a existência das prisões (Foucault, 2003). Deste modo, problematizá-las constitui urgência, não apenas para aqueles que estão dentro dos cárceres, mas principalmente para os que estão fora deles. Dentro e fora, aqui, cada vez revelando menos sentido. Paradoxos que constituem as racionalidades que aqui analisamos.

\section{Referências}

Alvarenga Filho, J. R. (2013). A Chacina do Pan: A produção de vidas descartáveis no Rio de Janeiro. Rio de Janeiro: Multifoco.

Arguello, K. (2007). Do Estado Social ao Estado Penal: invertendo o discurso da ordem. In Bittar, W.B. (Org.) A Criminologia do século XXI (pp. 119-144). Rio de Janeiro: Lumen Juris.

Baratta, A. (2002). Criminologia Crítica e Crítica do Direito Penal. Rio de Janeiro: Revan.

Brasil (1984). Lei de Execução Penal - Lei 7210 de 11 de julho de 1984.

Brasil (1941). Código de Processo Penal. Disponível em < http://www.planalto.gov.br/ccivil_03/ decreto-lei/Del3689Compilado.htm>. Acesso em: 10 out. 2014.

Carvalho, S. (2008). O Papel dos Atores do Sistema Penal na Era do Punitivismo. Rio de Janeiro: Lumen Juris.

CNPCP. Conselho Nacional de Política Criminal e Penitenciária (s.f.). Relatórios sobre inspeções feitas em estabelecimentos penais. Disponível em $<$ portal.mj.gov.br/cnpcp $>$.

Dornelles, J. R. (1992). O que é crime. São Paulo: Brasiliense.
Forrester, V. (1997). O Horror Econômico. São Paulo: Ed. UNESP.

Foucault, M. (2003). Vigiar e Punir: História da violência nas prisões. Petrópolis: Vozes.

Foucault, M. (2008). Nascimento da Biopolítica. São Paulo: Martins Fontes.

Kilduff, F. (2010). O controle da pobreza operado através do sistema penal. Katálysis, 13(2), 240-249.

Lourau, R. (1993). Análise Institucional e Práticas de Pesquisa. In Rodrigues, H. C. B. (Org.). René Lourau na UERJ (pp. 7-114). Rio de Janeiro: Ed. UERJ.

Pereira, V. F., \& Mezzalira, A. C. (2010). O Supremo Tribunal Federal e o prazo razoável da prisão preventiva. Âmbito Jurídico, 13(78), 5-19.

Reishoffer, J. C., \& Bicalho, P. P. G. (2015). A circunscrição histórica das prisões e a crítica criminológica. In Farias, F. R. \& Faceira, L. S. (Orgs). Punição e Prisão: ensaios críticos (pp. 13-26). Rio de Janeiro: Lumen Juris.

Rossotti, B. G. P. P., \& Bicalho, P. P. G. (2012). Por Outra Psicologia no Cárcere: presos provisórios, processos de criminalização e produção de subjetividade. In Martins, S.; Beiras, A., \& Cruz, R. M. (Orgs.). Reflexões e Experiências em Psicologia Jurídica no Contexto Criminal/ Penal (pp. 81-108). São Paulo: Vetor.

Scisleski, A. C. C., Reis, C., Hadler, O., Weigert, M. A. B., \& Guareschi, N. M. F. (2012). Juventude e pobreza: a construção de sujeitos potencialmente perigosos. Arquivos Brasileiros de Psicologia, 64(3), 19-34.

Wacquant, L. (1999/2011). As Prisões da Miséria. Rio de Janeiro: Zahar.

\section{Recebido: Outubro 16, 2015 Aprovado: Agosto 03, 2016}


